\title{
Declaración de la Academia Chilena de Medicina sobre la contaminación atmosférica de Santiago
}

\author{
Declaration of the Chilean Academy of Medicine \\ on atmosferic pollution in Santiago
}

1. La contaminación atmosférica de Santiago representa un serio problema de salud pública que afecta masivamente a la población. Esto ha venido siendo denunciado por la comunidad médica nacional desde hace más de cincuenta años. En efecto, en 1958, el Presidente de la Comisión de Investigaciones sobre Contaminaciones Atmosféricas de Estados Unidos de Norteamérica advirtió a los especialistas chilenos que Santiago estaba ya más contaminado que Nueva York, Filadelfia y otras ciudades americanas de mayor tamaño y grado de industrialización y en 1969 se publicaron los primeros estudios nacionales sobre este tema (Romero $\mathrm{H}$. Bol Academia de Medicina 1969; Oyanguren H et al: Rev Med Chile 1972 y 1979). El daño que producen los contaminantes atmosféricos, sean material particulado o gases tóxicos, no se limita a los pulmones, que son su puerta de entrada, sino que compromete a todo el organismo.

2. Las condiciones geográficas y meteorológicas de Santiago dificultan el recambio de su aire y favorecen la acumulación de contaminantes en su atmósfera. La progresiva expansión de la ciudad tiende a agravar el problema. Pero, además de Santiago, ya han sido declaradas zonas saturadas las ciudades de Tocopilla, $\mathrm{Pu}$ chuncaví-Ventanas, Rancagua, Talca, Temuco y Osorno y, si hubiera mediciones suficientes, lo estarían Curicó, Chillán, Valdivia, Puerto Montt y Coyhaique.

3. Como no es factible modificar las condiciones topográficas y climatológicas de las ciudades, a fin de controlar el nivel de contaminación sólo cabe disminuir las emisiones de contaminantes, sean sus fuentes móviles o fijas. Esto requiere de investigaciones específicas que precisen cuáles son los principales contaminantes y sus fuentes de emisión en cada ciudad

4. Santiago está expuesto casi permanentemente a niveles elevados de polución aérea, constituida en otoño e invierno predominantemente por material particulado $\left(\mathrm{PM}_{10}\right.$ y $\left.\mathrm{PM}_{2,5}\right)$, el que sistemáticamente excede la norma y es responsable de episodios críticos de contaminación. En tanto que en primavera y verano aumenta la concentración de oxidantes fotoquímicos, como el ozono, que sobrepasa frecuentemente las normas nacionales vigentes sobre la calidad del aire. Otros contaminantes que se elevan en el aire de Santiago son los hidrocarburos aromáticos policíclicos como componentes del material particulado y otros gases tóxicos, como el monóxido de carbono y el dióxido de nitrógeno, sales y metales. En otros lugares, especialmente en las zonas mineras e industriales, hay aumento de partículas y de anhídrido sulfuroso.

5. La red de monitoreo de la calidad del aire de Santiago y los periódicos inventarios de emisión han sido un importante avance en la cuantificación del problema e identificación de las principales fuentes de emisión. Sin embargo, es necesario perfeccionar esta red, extendiéndola y agregando la medición de otros contaminantes como los hidrocarburos aromáticos policíclicos, los metales y el ruido.

6. La contaminación atmosférica afecta la salud de las personas produciendo efectos agudos, ocasionados por concentraciones elevadas de partículas y gases que actuando por períodos cortos irritan las mucosas, favoreciendo infecciones y agravando enfermedades crónicas, pudiendo incluso llevar a la muerte. La conta- 
minación atmosférica transitoria, incluyendo el ruido, puede aumentar, además, la presión arterial y tener efectos psíquicos como irritabilidad, aumento de la agresividad y fatigabilidad física y mental. La contaminación del aire también puede ocasionar aumento de la incidencia y gravedad de enfermedades respiratorias y cardiovasculares crónicas. Además, hay efectos diferidos de la contaminación ambiental, como mutagénesis y carcinogénesis, que pueden presentarse mucho tiempo después del cese de la exposición y extenderse a futuras generaciones.

7. El efecto a corto y mediano plazo de los contaminantes está determinado fundamentalmente por la dosis efectiva, que es el producto de tres factores: tiempo de exposición, concentración aérea del contaminante y ventilación pulmonar. En episodios críticos se recomienda evitar el ejercicio físico para no aumentar la ventilación pulmonar, mantenerse en espacios cerrados y reducir la contaminación intra domiciliaria.

8. La contaminación intra domiciliaria depende de la infiltración de los agentes atmosféricos, sumados a la emisión de otros generados en el ambiente del domicilio, como el humo del tabaco y de los diversos artefactos contaminantes del hogar. Si no se controla la contaminación intra domiciliaria, ésta puede exceder a la atmosférica.

9. Grupos particularmente vulnerables a la contaminación atmosférica y que, por ende, requieren de protección especial son los menores de cinco años de edad, los enfermos cardiopulmonares crónicos, las embarazadas, así como los senescentes, población esta última en franco aumento.
10. La contaminación ambiental nos concierne a todos. Su solución dependerá de la voluntad política de las autoridades y del compromiso de toda la comunidad para aceptar y contribuir a las medidas para controlarla. Lamentablemente, es evidente que en esto hay poderosos intereses creados a los que hay que enfrentar en aras del bien común.

La Academia Chilena de Medicina reconoce que en Chile ha habido progresos en la lucha contra la contaminación ambiental, como es la institucionalidad sobre el tema, los avances en transporte público y privado, el desarrollo de carreteras urbanas, la instalación y aumento de las redes de monitoreo, los controles de las fuentes fijas, la imposición de normas más exigentes, la introducción del gas natural y otras regulaciones. Pero, todo lo anterior es insuficiente y urge intensificar las acciones contra esta desgracia que recae sobre toda la población.

Las medidas contra la contaminación atmosférica son sobradamente conocidas. Es urgente continuar en la senda trazada por el "Plan de prevención y descontaminación" puesto en marcha el año 1996, año en que Santiago fue declarada "zona saturada" y seguir rigurosamente los sucesivos y perfeccionados planes posteriores.

A juicio de la Academia Chilena de Medicina urge promover más investigaciones científicas y apoyar a los grupos de investigadores que se ocupan de este importante tema. Es, también, preciso hacer el máximo esfuerzo para que la comunidad tome cabal conciencia de la gravedad de la contaminación del aire en nuestras ciudades, para que participe y exija sin vacilaciones la primacía del bienestar de las personas sobre cualquier interés particular.

Santiago de Chile, 05 de septiembre de 2012 